
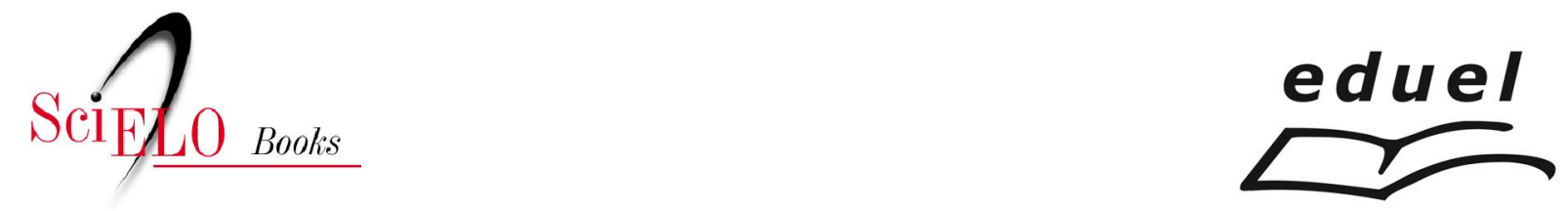

\title{
Rotina para a toxoplasmose na criança
}

\author{
Regina Mitsuka-Breganó \\ Fabiana Maria Ruiz Lopes-Mori \\ Italmar Teodorico Navarro \\ (orgs.)
}

\section{SciELO Books / SciELO Livros / SciELO Libros}

MITSUKA-BREGANÓ, R., LOPES-MORI, FMR., and NAVARRO, IT., orgs. Toxoplasmose adquirida na gestação e congênita: vigilância em saúde, diagnóstico, tratamento e condutas [online]. Londrina: EDUEL, 2010. Rotina para a toxoplasmose na criança. pp. 38-47. ISBN 978-85-7216-6768. Available from SciELO Books $<$ http://books.scielo.org $>$.

\section{(1) $(0)$}

All the contents of this work, except where otherwise noted, is licensed under a Creative Commons Attribution-Non Commercial-ShareAlike 3.0 Unported.

Todo o conteúdo deste trabalho, exceto quando houver ressalva, é publicado sob a licença Creative Commons Atribuição Uso Não Comercial - Partilha nos Mesmos Termos 3.0 Não adaptada.

Todo el contenido de esta obra, excepto donde se indique lo contrario, está bajo licencia de la licencia Creative Commons Reconocimento-NoComercial-CompartirIgual 3.0 Unported. 


\section{Rotina para a toxoplasmose na criança}

\section{Avaliação sorológica}

Realizar exame sorológico em todos os recém-nascidos de mães com toxoplasmose suspeita ou confirmada. Esse exame sorológico é imprescindível, tendo em vista que a maioria dos casos de toxoplasmose congênita é assintomática. 


\section{Classificação dos casos de acordo com a sorologia (algoritmo 3), segundo}

Lebech et al. (1996).

A) Caso suspeito.

- criança sintomática ou não cuja mãe apresentou toxoplasmose no curso da gestação;

- criança que nasce com sinais e sintomas da doença: icterícia, linfadenopatia, hepatoesplenomegalia, microcefalia, hidrocefalia, anemia, convulsões, baixo peso, prematuridade, retinocoroidite, calcificações cerebrais, nistagmo, estrabismo, microcefalia, iridociclite, alterações do líquor cefalorraquidiano, criança com anticorpos lgG reagente.

B) Caso confirmado: criança sintomática ou não que apresente pelo menos uma das situações abaixo:

- IgM ou IgA reagente após uma semana de vida;

- níveis séricos de lgG persistentemente elevados ou em ascensão;

- criança onde se confirmou a presença de T. gondii em tecido placentário ou fetal em cultivo de tecido ou bioensaio;

- criança cuja mãe apresentou PCR positiva no líquido amniótico.

C) Caso em investigação

- criança com níveis séricos de lgG em declínio e lgM não reagente após o sétimo dia de vida.

D) Caso Descartado

- criança com duas amostras de lgG não reagentes, com intervalo mínimo de três semanas e lgM não reagente. 


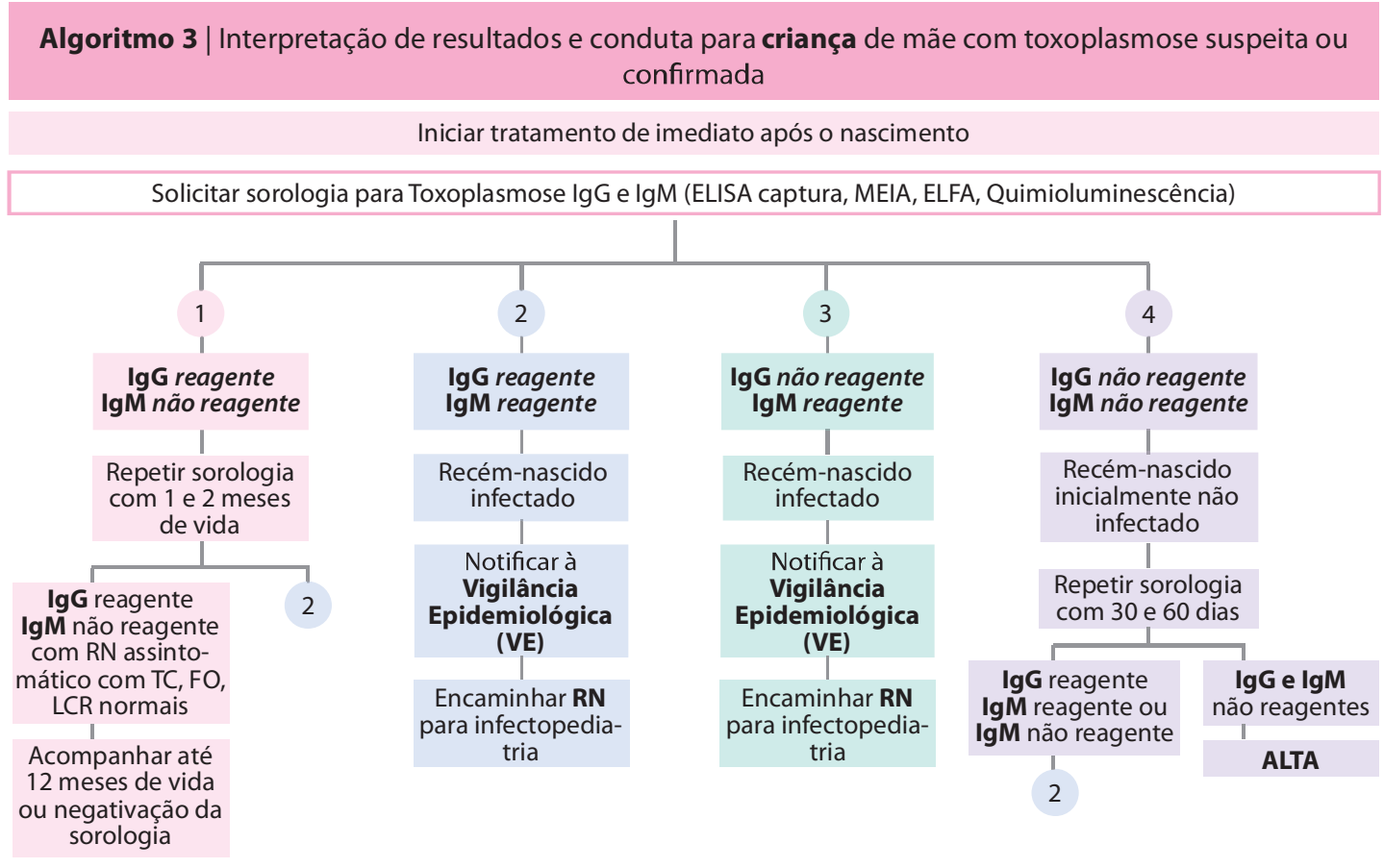

1 O seguimento sorológico definirá se há apenas transferência passiva de lgG maternos ou infecção. 


\section{Protocolo terapêutico para a toxoplasmose congênita}

O tratamento da toxoplasmose congênita está dividido em quatro protocolos (Quadros 8, $9,10$ e 11$)$ :

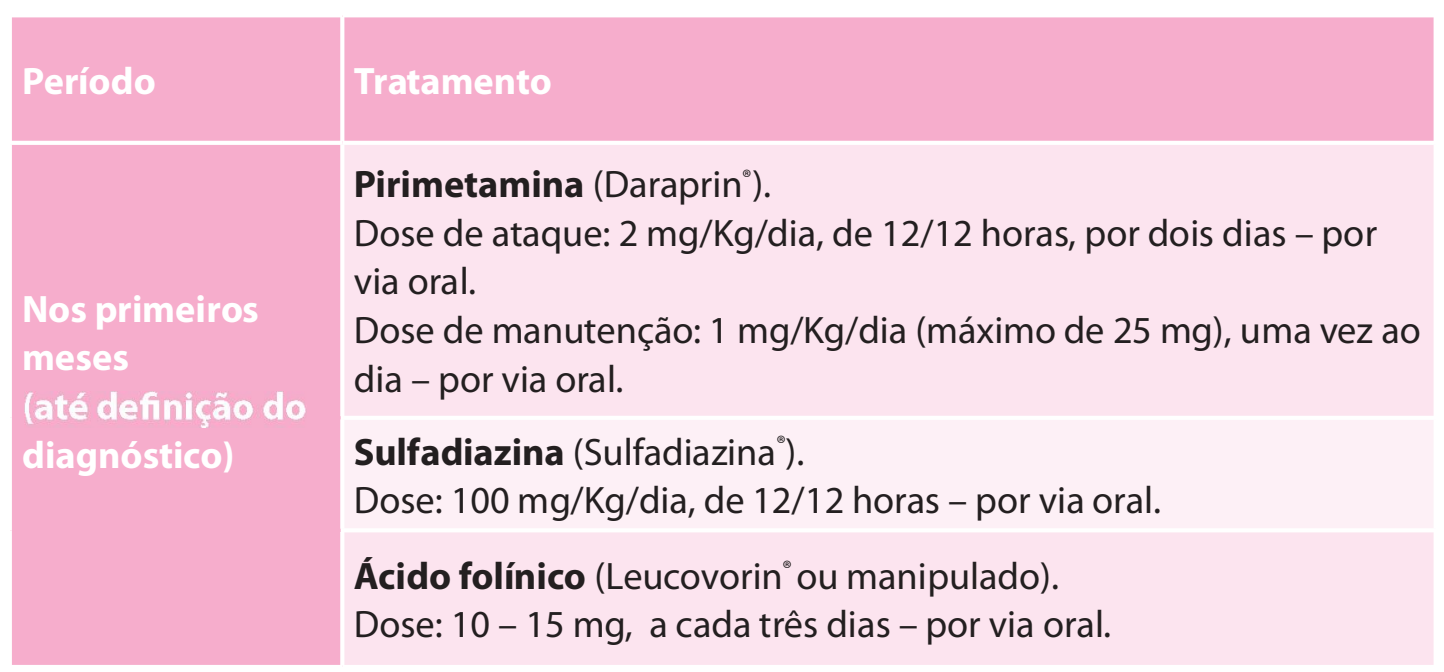

Em caso de toxicidade, ver o esquema terapêutico para criança no quadro 10.

Quadro 8 - Protocolo terapêutico de criança assintomática de mãe com infecção aguda confirmada ou suspeita na gravidez. (REMINGTON et al., 2006).

Observações:

- Investigar o caso e reavaliar a necessidade de continuar o tratamento.

- As medicações podem ser manipuladas em solução com cuidados de formulação e validade máxima de sete dias, nas concentrações: sulfadiazina $=100 \mathrm{mg} / \mathrm{ml}$, pirimetamina $=2 \mathrm{mg} / \mathrm{ml}$, ácido folínico $=10 \mathrm{mg} / \mathrm{ml}$.

- Recém-nascido pré-termo assintomático com dúvida no diagnóstico materno, deve iniciar tratamento com espiramicina (dose: 100mg/Kg/dia de 12 em 12 horas). 


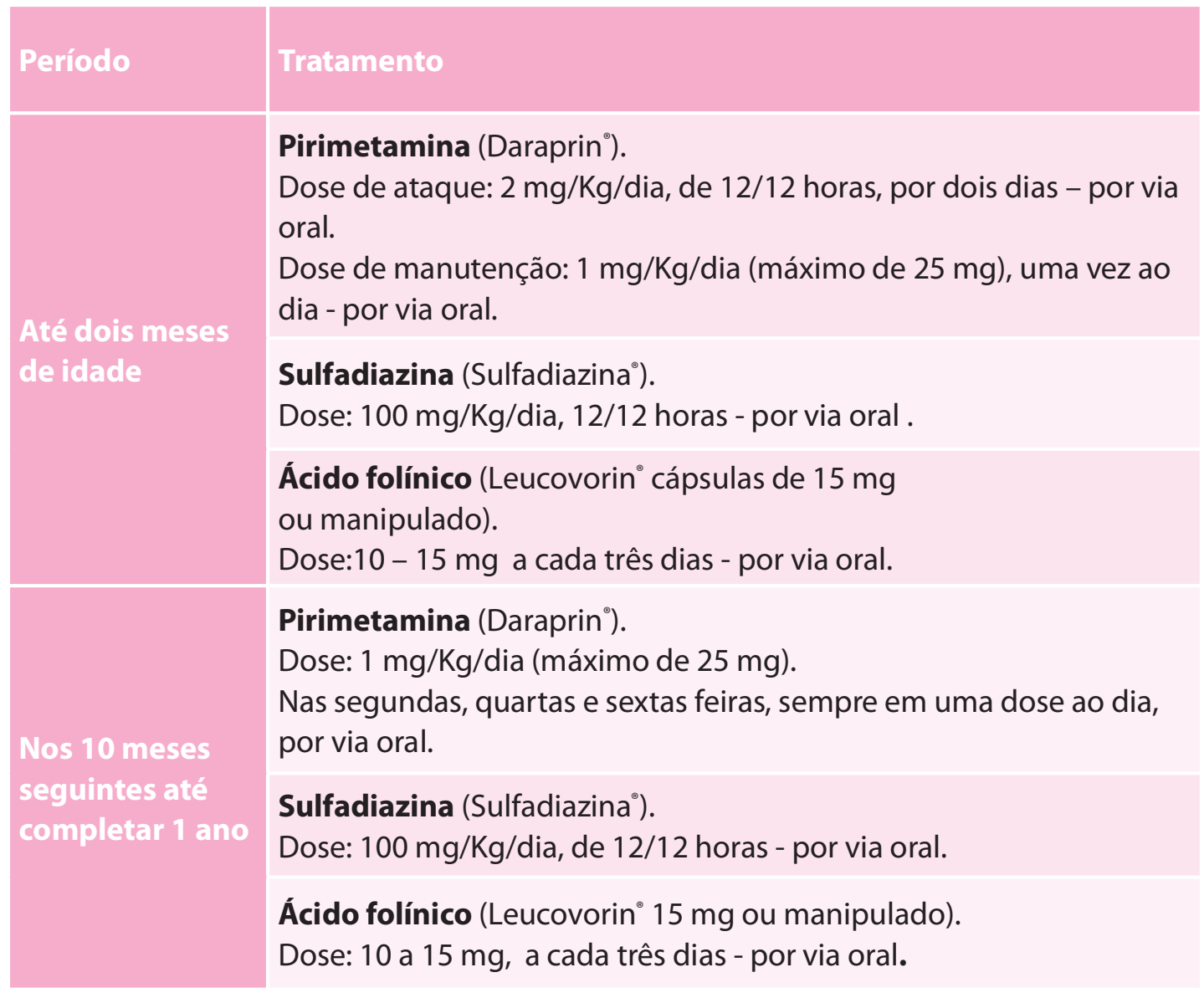

- Em casos graves pode-se estender o tratamento diário com pirimetamina em até seis meses, com posterior administração em dias alternados, até completar um ano de tratamento.

- Em caso de toxicidade, ver esquema terapêutico para criança no quadro 10.

Quadro 9 - Protocolo terapêutico de criança com toxoplasmose congênita confirmada. (REMINGTON et al., 2006). 


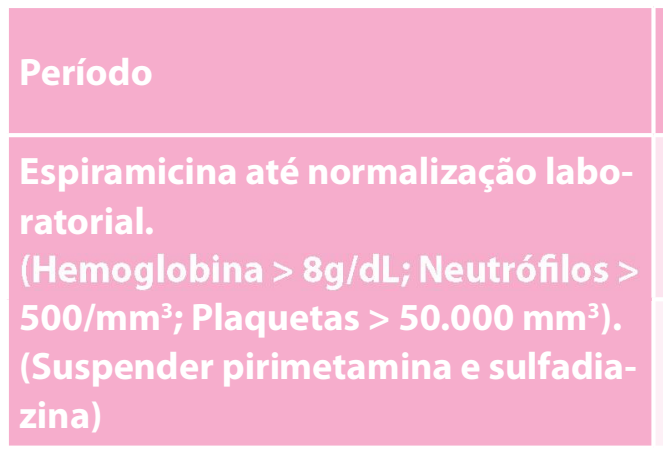

\section{Tratamento}

\section{Espiramicina (Rovamicina ${ }^{\circ}$.}

Dose: $100 \mathrm{mg} / \mathrm{Kg} / \mathrm{dia}$, de 12/12 horas - por via oral.

Aumentar a dose do ácido folínico para 15 a 30 $\mathrm{mg} / \mathrm{dia}$.

Quadro 10 - Protocolo terapêutico para a criança com toxicidade medular grave. (REMINGTON et al., 2006).

\section{Observações:}

- Considerar alternância de espiramicina (três semanas) com sulfadiazina + pirimetamina + ácido folínico (quatro semanas), caso haja recorrência de toxicidade medular.

- Considerando que a espiramicina pode causar alargamento de QT, realizar Eletrocardiograma (ECG) no primeiro dia de uso da espiramicina e depois, de 15 em 15 dias, até 45 dias de vida. Caso seja necessário manter mais tempo de uso da espiramicina, realizar ECG mensal se não houver alterações ou queixa clínica.

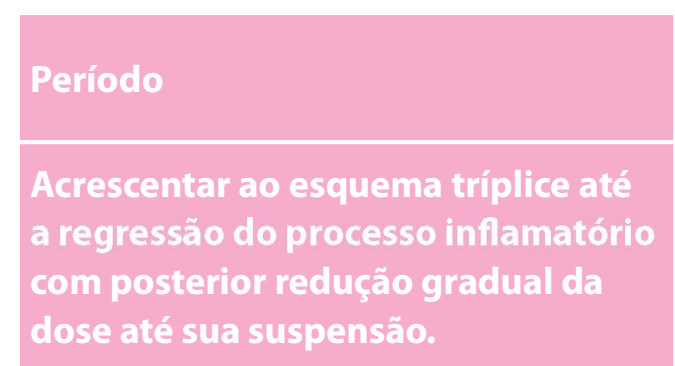

\section{Tratamento}

Prednisona (Meticorten ${ }^{\circ}$.

Dose: 1,0 mg/Kg/dia, de 12/12 horas - por via oral (associado ao esquema tríplice).

Quadro 11 - Protocolo terapêutico para a criança com retinocoroidite ativa e/ou proteína no líquido cefalorraquidiano $\geq 1 \mathrm{~g} / \mathrm{dL}$. (REMINGTON et al., 2006). 


\section{Controle dos efeitos adversos}

A sulfadiazina e a pirimetamina, sinergicamente, inibem as etapas sequenciais da biossíntese do equivalente do ácido folínico exigido pelo T. gondii. São drogas antagonistas do ácido fólico e a utilização diária delas implica distúrbios hematológicos. Por isso, é indispensável que o tratamento seja acompanhado de realização periódica de hemograma completo e contagem de plaquetas. Além desse acompanhamento, deve ser administrado ácido folínico, concomitantemente, como medida preventiva destes distúrbios, uma vez que os mamíferos conseguem utilizar o ácido folínico, mas o T. gondii não (ver protocolos terapêuticos).

Durante o acompanhamento hematológico, se o paciente apresentar neutropenia, plaquetopenia, leucopenia ou pancitopenia, o tratamento com pirimetamina e sulfadiazina deve ser suspenso até a normalização dos exames laboratoriais. Durante este período, o tratamento deve ser com o uso de espiramicina. Na eventualidade do uso deste antibiótico macrolídeo, o bebê deve ser submetido a um ECG, para verificar se não é portador de aumento do intervalo QT, situação em que pode ocorrer arritmia cardíaca com o uso desta classe de antibióticos.

\section{Avaliação da toxicidade}

Pirimetamina: realizar contagem de hemácias, leucócitos e plaquetas uma vez por semana nas primeiras duas semanas de tratamento com pirimetamina. Se a contagem for estável nas primeiras semanas, espaçar o controle hematológico para duas vezes por mês. Quando o uso de pirimetamina for em dias alternados, realizar os exames uma vez por mês, a não ser que ocorra alteração nos resultados dos exames realizados.

Se ocorrer infecção viral intercorrente, principalmente febril, o controle deve ser mais frequente, pois as infecções virais tendem a provocar diminuição no número de neutrófilos (neutropenia).

A conduta varia de acordo com a contagem de neutrófilos:

- Se maior que $1000 / \mathrm{mm}^{3}$ : manter tratamento com o esquema tríplice. 
- Entre 500 a 900/mm³ : aumentar ácido folínico para 15 a 30 mg/dia.

- Se menor que $500 / \mathrm{mm}^{3}$ : suspender pirimetamina e sulfadiazina, iniciar espiramicina e aumentar ácido folínico para 15 a 30 mg ao dia.

Reiniciar esquema tríplice quando a contagem estiver maior que 1000/mm³.

Reações adversas:

- Pirimetamina: depressão da medula óssea (efeito gradual, reversível e dose dependente), discrasiassanguíneas, deficiência doácidofólico, anemiamegaloblástica e, raramente, exantema, vômitos, convulsões, choque e eosinofilia pulmonar.

- Sulfadiazina: cristalúria, anemia hemolítica, agranulocitose e plaquetopenia (reversíveis na maioria dos casos) e reações de hipersensibilidade.

- Espiramicina: distúrbios gastrintestinais, como diarreia, vômitos, náuseas, dor abdominal e reações alérgicas.

\section{Condutas}

\section{Maternidade}

A) Avaliação clínica (médico infectopediatra), oftalmológica e neurológica (se apresentar alterações neurológicas).

- Teste do potencial evocado (realizado preferencialmente no primeiro mês de vida)

B) Avaliação laboratorial:

- Hemograma, plaquetas, bilirrubina total e frações, aminotransferases (AST, ALT) e avaliação do líquido cefalorraquidiano (LCR);

- ultrassonografia ou tomografia computadorizada de crânio; na impossibilidade de realização desses exames fazer Raio X de crânio;

- sorologia: pesquisa de anticorpos anti-T. gondii lgG e lgM;

- iniciar tratamento empírico - até confirmação do diagnóstico. 


\section{Ambulatorial}

A) Retorno em uma semana com os resultados dos exames hemograma e plaquetas:

- manter tratamento empírico.

B) Retorno em duas semanas:

- solicitar: hemograma, plaquetas, AST, ALT, sorologia anti-T. gondii (IgG IgM);

- manter tratamento empírico.

C) Retorno após 30 dias de vida:

- manter o tratamento;

- solicitar hemograma e plaquetas com 45 dias e depois mensalmente;

- solicitar AST e ALT conforme a evolução;

- solicitar LCR de controle se o inicial estiver alterado;

- solicitar sorologia anti-T. gondii lgG e lgM, para os casos inconclusivos e, se necessário, repetir novamente com três semanas de intervalo. Para os casos confirmados, repetir a sorologia com um ano de tratamento e com 15 meses de vida;

- crianças em que é excluído o diagnóstico e suspenso o tratamento devem realizar sorologia para toxoplasmose de dois em dois meses até a negativação da lgG;

- criança com dilatação de sistema ventricular no exame inicial: encaminhar para avaliaçãoneuropediátrica que definiráa periodicidade dos exames de ultrassonografia e tomografia computadorizada de crânio;

- avaliação audiométrica, se o teste do potencial evocado for alterado ou indisponível na maternidade.

D) Retornos até um ano de idade:

- retorno mensal até completar um ano de tratamento;

- acompanhamento do perímetro cefálico;

- avaliação neuropediátrica; 
- avaliação oftalmológica mensal até a exclusão de infecção congênita;

- avaliação audiométrica.

E) Retorno anual para avaliação clínica até os cinco anos idade:

- seguimento concomitante com as demais especialidades médicas.

F) Acompanhamento oftalmológico em crianças com toxoplasmose congênita confirmada:

- avaliação trimestral até 18 meses de idade;

- semestral até os cinco anos de idade;

- anual até a adolescência.

G) Anotar no cartão da criança todos os resultados de exames laboratoriais, com a data, os métodos utilizados e seus respectivos valores de referência, o início do tratamento, medicamentos e o esquema terapêutico utilizado.

Os casos suspeitos, confirmados e em investigação devem ser notificados à Vigilância Epidemiológica local, onde será preenchida a ficha de investigação epidemiológica para toxoplasmose.

A inclusão da toxoplasmose no Programa de Triagem Neonatal, complementar à triagem materna, foi sugerida por vários especialistas como forma de corrigir possíveis falhas no diagnóstico materno. A triagem neonatal poderia diagnosticar os casos de toxoplasmose congênita em crianças de mães que não realizam o pré-natal regularmente, bem como os casos em que a gestante adquire infecção após a realização da última sorologia, fase em que a taxa de transmissão fetal é maior. (LAGO et al., NETO et al., 2004). 